\title{
Theoretical Studies on Pyrazole DeRivatives AS ANTI-BREAST CANCER AgENTS: DFT, QSAR AND DOCKING METHODS
}

\author{
Banjo Semire* and Abel Kolawole Oyebamiji \\ Department of Pure and Applied Chemistry, Faculty of Pure and Applied Sciences, Ladoke Akintola \\ University of Technology, Ogbomoso, Oyo State, Nigeria \\ *E-mail: bsemire@1autech.edu.ng \\ Tel.: +2348038269809 .
}

Received: Dec 08, 2017 / Revised: Dec 21, 2017 / Accepted: Dec 22, 2017

\begin{abstract}
Pyrazole derivatives as anti-cancer agents were observed using Density functional theory (DFT), Quantitative Structure Activity Relation (QSAR) and docking method. The molecular descriptors obtained from DFT were used to develop QSAR model so as to predict their cytotoxicity. Therefore, the predicted IC 50 obtained from modeled QSAR fitted well the experimental IC ${ }_{50}$. Also, the calculated molecules were docked against breast cell line and the molecular binding energy which resulted from the interaction showed the level of their affinity.
\end{abstract}

Key words: Pyrazole derivatives, DFT, QSAR, Docking.

\section{INTRODUCTION}

The breast cancer as the second leading cause of death throughout the world, is still the most frequently identified cancer in women. Recently, it was estimated that 252,710 women were diagnosed of this malignant neoplasia and death of 40,610 women were reported by American Cancer Society (Breast Cancer Facts \& Figures, 2017-2018). Despite the substantial developments made to cure early breast cancer, medical defies still remain (Oyebamiji and Semire, 2016a; Bayani et al 2017). The possible risk factors in breast cancer are gender, family history, genetics, and age (Aghaee et al 2012). The possible available cures for breast cancer comprise chemotherapy, radiation therapy, surgery, hormonal therapy, or combination therapy (Oyebamiji and Semire, 2016b; Jemal et al 2011). Therefore, many research works have concentrated on the area of drug resistance so as to enhance cancer chemotherapy (Gottesman, 2002; Harris et al 2000).

Pyrazole contains an unsaturated five membered ring with two nitrogen atoms which are adjacent to each other. Although many heterocyclic moieties like imidazole, coumarin, benzimidazole, quinazolinone etc. are associated with pharmacological activities (Dahiya and Kumar, 2008; Dahiya et al 2008; 2010; Dahiya and Mourya, 2013; Dahiya and Pathak, 2007) but due to the interested biological activities like anticancer (Balbi et al 2011), antifungal (Prakash et al 2008), analgesic (Pereira et al 1998), antiviral (Storer et al 1999), pyrazoles have attracted the attention of the researchers. The pyrazole moiety has other significant role such as, arylpyrazole derivatives with anti-HIV ability and pyrazole-3-carboxamide derivatives with anti-CB1 cannabinoid capacity (Genin et al 2000; Ruiu et al 2003). Also, in crop protection chemistry, pyrazole derivatives have numerous uses.

Quantitative structural activity relationship (QSAR) models are very valuable regression simulations in the biological sciences analysis (Oyebamiji and Semire, 2016c; Sharma et al 2016; Agarwal et al 2015a; 2015b; Bansal et al 2011). It is an arithmetic model which link 
physicochemical parameters of a chemical compound to its biological activity (Hansch, 1969). Thus, the development of a good and effective QSAR model is a function of higher quality data and the choice of descriptors.

Docking as a developing vital scheme for drug discovery is a key device in computer-based drug design (Sharma et al 2011; Balasubramanian and Vijaya Gopal, 2012; Jain et al 2013; Sharma and Kumar, 2014). It helps in the understanding of the interaction between the molecular compounds and the enzymes by identifying the suitable active gouge in enzyme. In docking study, the strength of the contact which is in statistical form between the molecular compounds and the enzymes can be calculated and presented as dock score (Taylor et al 2002). Present research work comprises of twenty synthesized molecules (Hafez et al 2016), as shown in Figure 1. These compounds which were optimized using density functional theory (DFT) via 6-31G $(d, p)$ basis set, were vetted against MCF-7 (human breast cancer) cell line so as to obtain molecular parameters.

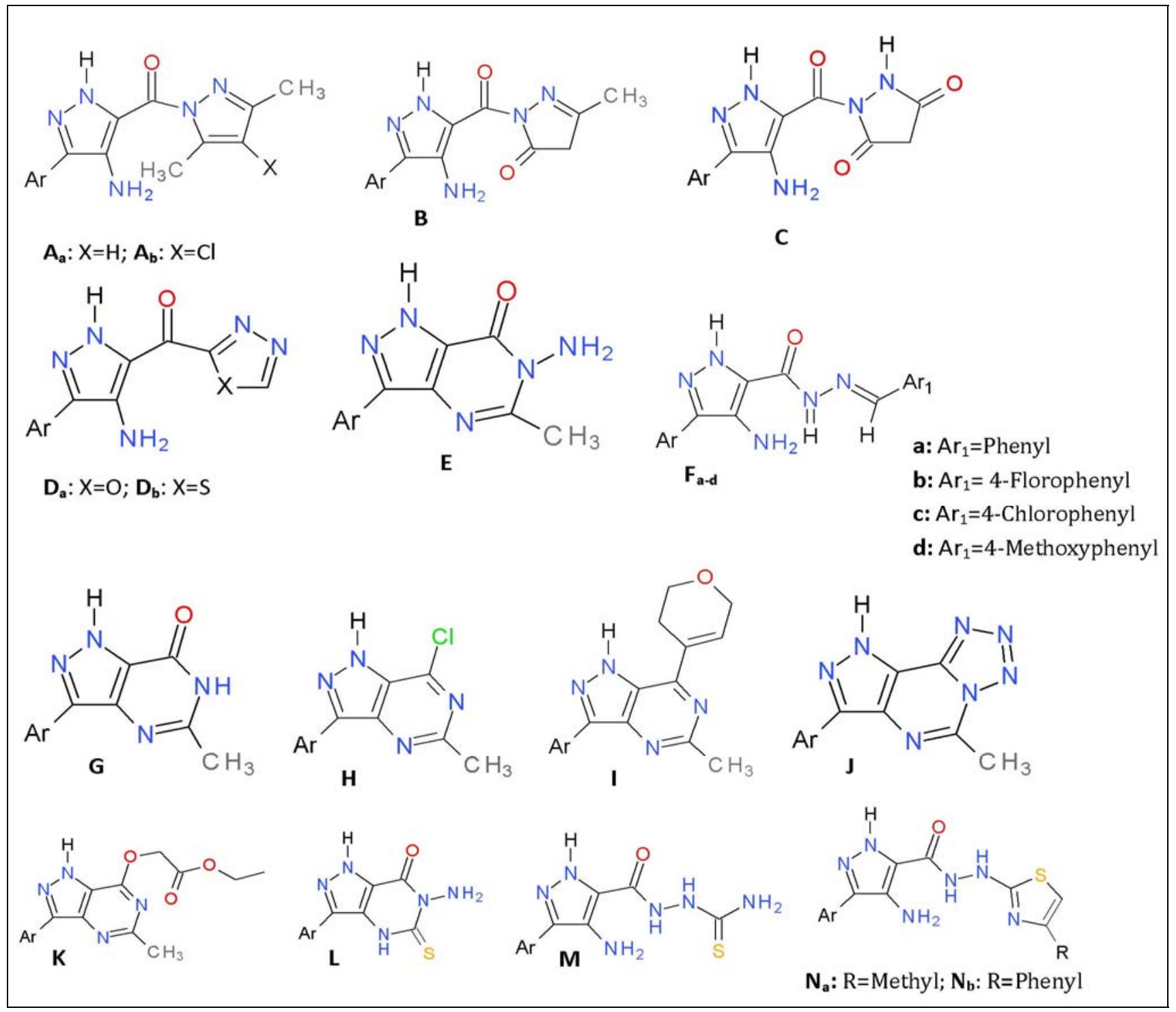

Fig. 1. The schematic structures of the studied molecules

These molecular compounds include 4-amino-3(4-chlorophenyl)- 1H -pyrazolyl-5-yl - (3,5-dimethyl-1H-pyrazol-1-yl) derivatives) methanone $\mathbf{A}_{\mathbf{a}, \mathbf{b}}, \quad 2-\{[4$-amino-3- (4-chloro phenyl)- $1 \mathrm{H}$ pyrazol-5-yl] carbonyl\}- 5-methyl-2,4-dihydro3H-pyrazol-3-one B, 1-\{[4-amino-3-(4-chlorophenyl-1H-pyrazol-5-yl]carbonyl $\}$ pyrazolidine- 3,5-dione C, 3-(4-chlorophenyl)-5-(1,3,4-oxa/ thiadiazol-2yl) -1H- pyrazol-4-amine $\mathbf{D}_{\mathbf{a}, \mathbf{b}}, \quad 6-$ amino-3-(4-chloro phenyl)-5-methyl-1,6-dihydro-7H-pyrazolo-[4,3-d]pyrimidin-7-one E, 4amino-3-(4-chlorophenyl)-N'-[arylmethylidene]1H-pyrazole-5-carbhydrazide $\mathbf{F}_{\text {a-d }}$, 3-(4-chlorophenyl)-5-methyl-1,6-dihydro-7H-pyrazolo [4,3- 
d]pyrimidine-7-one G, 7-chloropyrazolo[4,3d]pyrimidine $\mathbf{H}, \quad 3$-(4-chlorophenyl)-7-(3,6dihydro-2H-pyran-4-yl)-5-methyl -1H- pyrazolo[4,3-d]pyrimidine I, 7-(4-chloro phenyl)-5methyl-9H-pyrazolo [3,4-e] tetrazolo [1,5-c]pyrimidine J, Ethyl \{[3-(4-chloro phenyl)-5methyl-1H-pyrazolo[4,3-d]pyrimidine-7-yl]oxy\} acetate K, 6-amino-3-(4-chlorophenyl)-5-thioxo1,4,5,6-tetrahydro-7 H-pyrazolo[4,3-d]pyrimidin7-one L, 2-\{[4-amino-3-(4-chloro phenyl)-1Hpyrazol-5-yl] carbonyl $\}$ hydrazinecarbothioamide M, 4-amino-3-(4-chlorophenyl)-N'-(4methyl/ or 4-phenyl-1,3-thiazol-2-yl)-1Hpyrazole-5-carbohydrazide $\mathbf{N}_{\mathbf{a}, \mathbf{b}}$. Moreover, this paper is aimed to obtain molecular parameters using DFT method and use the selected parameters to develop QSAR model which predicts experimentally observed bioactivity. Likewise, it is to find the binding affinity from the interaction between the ligand and the receptor [MCF-7 (PDB: 1HI7)] via docking.

\section{Computational details}

\section{Quantum chemical method}

Density Functional Theory (DFT) with 6-31G** as basis set was used for the equilibrium geometry optimization of the studied twenty compounds $\left(\mathbf{A}_{\mathbf{a}}-\mathbf{N}_{\mathbf{b}}\right)$. This method consists of the three-parameter density functional, which includes Becke's gradient exchange correction (Becke, 1993) and the Lee, Yang, Parr correlation functional (Lee et al 1988). The choice of the functional and basis sets chosen was ascribed to the accurateness of DFT calculations; thus the sufficiency of a polarized split valence $6-31 \mathrm{G}^{* *}$ as basis set has been ascertained for calculations of the properties of molecular compounds (Jacquemin et al 2009); therefore, in this research work 6-31G** basis set was used. Moreover, the molecular compounds studied in this research work were optimized using Spartan' 14 by wave function Inc (Spartan 14) in order to get molecular descriptors (highest occupied molecular orbital (HOMO), lowest unoccupied molecular orbital (LUMO), chemical hardness, chemical potential, global nucleophilicity, and solvation energy) and observed its biological activities. Also, the molecular compounds which were optimized, were used for the docking study.

\section{QSAR model using multiple linear regressions}

The obtained calculated descriptors were used to develop quantitative structure-activity relationship (QSAR) model in order to investigate its biological activities (Pourbasheer et al 2009). Multiple linear regression method, a frequent statistical procedure used in making QSAR model was used to realize this. Furthermore, the validation of the developed QSAR model was achieved by observing some statistical equations like cross validation $\left(R^{2}\right)$ and adjusted $\mathrm{R}^{2}$ as shown in equation 1 :

$$
C V \cdot R^{2}=1-\frac{\sum\left(o b s^{-} c a l\right)^{2}}{\sum\left(o b s^{-} o b s\right)^{2}}
$$

The $\mathrm{R}^{2}$ adjusted could be calculated using equation (2):

$$
R_{a}^{2}=\frac{(N-I) \times R^{2}-P}{N-1-P}
$$

\section{Docking and scoring}

The receptor used [MCF-7 (PDB: 1HI7)] (Williams et al 2001) was downloaded from protein data bank and it was treated using discovery studio. Also, the ligand and the treated enzyme were both converted to the format (pdbqt) acceptable by autodockvina via autodock tool. Then the docking calculation was carried out by autodockvina which was stirred by Darwinian evolution theory to be repeated optimization method (Rani et al 2014).

\section{RESULTS AND DISCUSSION Molecular descriptors}

Solvation energy, weight, hydrophobicity (Log $\mathrm{P})$, volume (V), Area, polar surface area (PSA), ovality, dipole moment (DM), heteroatoms (average of mulliken charges on all heteroatoms), HOMO, and LUMO energies were the molecular descriptors calculated for this study. The highest occupied molecular orbital (HOMO) were $-5.54 \mathrm{eV},-5.66 \mathrm{eV},-5.87 \mathrm{eV},-6.58 \mathrm{eV}$, $-5.74 \mathrm{eV}, \quad-5.66 \mathrm{eV},-5.96 \mathrm{eV},-5.84 \mathrm{eV},-5.84 \mathrm{eV}$, $-6.07 \mathrm{eV},-5.56 \mathrm{eV},-5.99 \mathrm{eV}, \quad-6.23 \mathrm{eV}, \quad-5.91 \mathrm{eV}$, $-5.91 \mathrm{eV}, \quad-5.88 \mathrm{eV},-6.18 \mathrm{eV},-5.79 \mathrm{eV},-5.73 \mathrm{eV}$, $-5.7 \mathrm{eV}$ for compounds $\mathbf{A}_{\mathbf{a}}-\mathbf{N}_{\mathbf{b}}$ respectively. Similarly, the lowest unoccupied molecular orbital (LUMO) energy were $-1.66 \mathrm{eV}$ for $\mathbf{A}_{\mathbf{a}}$, $-1.85 \mathrm{eV}$ for $\mathbf{A}_{\mathbf{b}},-1.6 \mathrm{eV}$ for $\mathbf{B},-1.94 \mathrm{eV}$ for $\mathbf{C}$, $-1.41 \mathrm{eV}$ for $\mathbf{D}_{\mathbf{a}},-1.8 \mathrm{eV}$ for $\mathbf{D}_{\mathbf{b}},-1.36 \mathrm{eV}$ for $\mathbf{E}$, $-0.82 \mathrm{eV}$ for $\mathbf{F}_{\mathbf{a}},-1.65 \mathrm{eV}$ for $\mathbf{F}_{\mathbf{b}},-1.8 \mathrm{eV}$ for $\mathbf{F}_{\mathbf{c}}$, $-1.44 \mathrm{eV}$ for $\mathbf{F}_{\mathrm{d}},-1.31 \mathrm{eV}$ for $\mathbf{G},-2.09 \mathrm{eV}$ for $\mathbf{H}$, $-2.09 \mathrm{eV}$ for $\mathbf{I},-1.99 \mathrm{eV}$ for $\mathbf{J},-1.45 \mathrm{eV}$ for $\mathbf{K},-1.89 \mathrm{eV}$ for $\mathbf{L},-1.41 \mathrm{eV}$ for $\mathbf{M},-1.24 \mathrm{eV}$ for $\mathbf{N}_{\mathrm{a}},-1.3 \mathrm{eV}$ for $\mathbf{N}_{\mathbf{b}}$. Furthermore, HOMO together with LUMO provides substantial qualitative facts about the molecular excitation properties (Bouachrine et 
al 2009; Yang et al 2005). In this research work, no correlation between HOMO as well as LUMO and bioactivity of pyrazole was detected. Also, the band gap which is basically the relics of energy series that are not enclosed by band (Harisson, 1966), are $3.98 \mathrm{eV}, 3.81 \mathrm{eV}, 4.27 \mathrm{eV}$, $4.64 \mathrm{eV}, 4.33 \mathrm{eV}, 3.86 \mathrm{eV}, 4.6 \mathrm{eV}, 5.02 \mathrm{eV}, 4.33 \mathrm{eV}$, $4.27 \mathrm{eV}, 4.12 \mathrm{eV}, 4.68 \mathrm{eV}, 4.14 \mathrm{eV}, 3.82 \mathrm{eV}, 4.39 \mathrm{eV}$, $4.43 \mathrm{eV}, 4.29 \mathrm{eV}, 4.38 \mathrm{eV}, 4.49 \mathrm{eV}$ and $4.4 \mathrm{eV}$ for $\mathbf{A}_{\mathbf{a}}-$ $\mathbf{N}_{\mathbf{b}}$ as displayed in Table 1. It is believed that, the band gap would play a significant part that can't be ignored, because lower band gap brings about easier excitation together with better proficiency of a compound to donate an electron(s) to the adjoining molecules; however, as observed in this research, there is no effective correlation between the band gap and biological activities of pyrazole derivatives. Furthermore, calculated Log $\mathrm{P}$ reveals the abilities of molecular compounds to relax in non-aqueous solution (Abass et al 2011).

Thus, problem may likely arise, if the administered molecules have Log $\mathrm{P}$ to be greater than 5 (Meanwell, 2011). The calculated Log P are 0.07 for $\mathbf{A}_{\mathbf{a}},-0.06$ for $\mathbf{A}_{\mathbf{b}},-1.01$ for $\mathbf{B},-1.52$ for C, 0.26 for $\mathbf{D}_{\mathbf{a}}, 0.83$ for $\mathbf{D}_{\mathbf{b}},-0.15$ for $\mathbf{E}, 0.6$ for $\mathbf{F}_{\mathbf{a}}$, 0.62 for $\mathbf{F}_{\mathbf{b}}, 2.02$ for $\mathbf{F}_{\mathbf{c}}, 1.34$ for $\mathbf{F}_{\mathbf{d}}, 0.1$ for $\mathbf{G}, 1.55$ for $\mathbf{H}, 1.67$ for $\mathbf{I}, 1.83$ for $\mathbf{J}, 0.76$ for $\mathbf{K}, 0.15$ for $\mathbf{L}$, 0.96 for $\mathbf{M}, 0.09$ for $\mathbf{N}_{\mathrm{a}}, 1.49$ for $\mathbf{N}_{\mathbf{b}}$, therefore, the molecules used in this work are proficient in term of lipophilicity. Moreover, the calculated dipole moment are 5.26 Debye, 3.33 Debye, 6.35 Debye, 2.54 Debye, 3.51 Debye, 3.76 Debye, 4.23 Debye, 5.19 Debye, 1.68 Debye, 1.81 Debye, 2.91 Debye, 4.11 Debye, 2.26 Debye, 4.67 Debye, 0.76 Debye, 6.68 Debye, 3.02 Debye, 4.84 Debye, 4.68 Debye, 4.39 Debye for $\mathbf{A}_{\mathbf{a}}-\mathbf{N}_{\mathbf{b}}$ respectively; and this explains the product of the charge degree as well as the distance of separation between the charges (McMurry and Fay, 2004).

Therefore, in term of dipole moment, most of the ligands are likely to have firm nonbonded interactions with the receptor, only for $\mathbf{A}_{\mathbf{a}}, \mathbf{B}$ and $\mathbf{F}_{\mathbf{a}}$ that are beyond the accepted range (3 to $5 \mathrm{~kJ} / \mathrm{mol}$ ) (Lewis and Broughton, 2002). The heteroatom, ovality, area, and volume were also calculated in this research work (Table 1).

Table 1. The calculated molecular descriptors from the compounds $\mathbf{A}_{\mathbf{a}}-\mathbf{N}_{\mathbf{b}}$ for anti-breast cancer

\begin{tabular}{|c|c|c|c|c|c|c|c|c|c|c|}
\hline $\mathbf{M O L}$ & $\mathbf{H O M O}$ & $\mathbf{L U M O}$ & $\mathbf{B G}$ & $\mathbf{D M}$ & $\mathbf{S . E}$ & $\mathbf{n}$ & $\boldsymbol{\mu}$ & $\mathbf{G N}$ & $\mathbf{H}$ & $\mathbf{N + N}$ \\
\hline $\mathbf{A}_{\mathbf{a}}$ & -5.54 & -1.66 & 3.98 & 5.26 & -0.01289 & 3.6 & -1.94 & 0.5227 & -1.0204 & -0.758 \\
\hline $\mathbf{A}_{\mathbf{b}}$ & -5.66 & -1.85 & 3.81 & 3.33 & -0.01208 & 3.755 & -1.905 & 0.4832 & -1.0111 & -0.758 \\
\hline $\mathbf{B}$ & -5.87 & -1.6 & 4.27 & 6.35 & -0.02134 & 3.735 & -2.135 & 0.6102 & -0.9578 & -0.705 \\
\hline $\mathbf{C}$ & -6.58 & -1.94 & 4.64 & 2.54 & -0.03482 & 4.26 & -2.455 & 0.7074 & -0.938 & -0.709 \\
\hline $\mathbf{D}_{\mathbf{a}}$ & -5.74 & -1.41 & 4.33 & 3.51 & -0.02187 & 3.575 & -2.165 & 0.6556 & -0.9172 & -0.795 \\
\hline $\mathbf{D}_{\mathbf{b}}$ & -5.66 & -1.8 & 3.86 & 3.76 & -0.01747 & 3.73 & -1.93 & 0.4993 & 0.2134 & -0.798 \\
\hline $\mathbf{E}$ & -5.96 & -1.36 & 4.6 & 4.23 & -0.01815 & 3.66 & -2.3 & 0.7227 & -1.0292 & -0.81 \\
\hline $\mathbf{F}_{\mathbf{a}}$ & -5.84 & -0.82 & 5.02 & 5.19 & -0.01575 & 3.33 & -2.51 & 0.946 & -0.9988 & -0.736 \\
\hline $\mathbf{F}_{\mathbf{b}}$ & -5.84 & -1.65 & 4.33 & 1.68 & -0.01442 & 3.815 & -2.165 & 0.6143 & -1.489 & -0.735 \\
\hline $\mathbf{F}_{\mathbf{c}}$ & -6.07 & -1.8 & 4.27 & 1.81 & -0.01671 & 3.935 & -2.135 & 0.5792 & -0.9649 & -0.753 \\
\hline $\mathbf{F}_{\mathbf{d}}$ & -5.56 & -1.44 & 4.12 & 2.91 & -0.01841 & 3.5 & -3.1275 & 1.3973 & -0.9946 & -0.736 \\
\hline $\mathbf{G}$ & -5.99 & -1.31 & 4.68 & 4.11 & -0.01977 & 3.65 & -2.34 & 0.7501 & -1.0293 & -0.801 \\
\hline $\mathbf{H}$ & -6.23 & -2.09 & 4.14 & 2.26 & -0.01402 & 4.16 & -2.07 & 0.515 & -0.9957 & -0.826 \\
\hline $\mathbf{I}$ & -5.91 & -2.09 & 3.82 & 4.67 & -0.01784 & 4 & -1.91 & 0.456 & -0.345 & -0.853 \\
\hline $\mathbf{J}$ & -5.91 & -1.99 & 4.39 & 0.76 & -0.01789 & 4.185 & -2.195 & 0.5756 & -0.4787 & -0.848 \\
\hline $\mathbf{K}$ & -5.88 & -1.45 & 4.43 & 6.68 & -0.01861 & 3.665 & -2.215 & 0.6693 & -0.7108 & -0.836 \\
\hline $\mathbf{L}$ & -6.18 & -1.89 & 4.29 & 3.02 & -0.02548 & 4.035 & -2.145 & 0.5701 & -0.7108 & -0.781 \\
\hline $\mathbf{M}$ & -5.79 & -1.41 & 4.38 & 4.84 & -0.03355 & 3.6 & -2.19 & 0.6661 & -1.3475 & -0.792 \\
\hline $\mathbf{N}_{\mathbf{a}}$ & -5.73 & -1.24 & 4.49 & 4.68 & -0.02043 & 3.485 & -2.245 & 0.7231 & -1.0347 & -0.743 \\
\hline $\mathbf{N}_{\mathbf{b}}$ & -5.7 & -1.3 & 4.4 & 4.39 & -0.02085 & 3.485 & -2.2 & 0.6914 & -0.7948 & -0.742 \\
\hline
\end{tabular}

\section{QSAR model}

Multiple linear regression method was used to make QSAR analysis so as to explore the structural activity relationship of 20 pyrazole derivatives with anti-cancer ability. Therefore, 15 parameters were involved in making the model for the prediction of highly fitted $\mathrm{IC}_{50}$. The developed equation is shown in equation 3. 
Thus, the developed model was used to predict and the results are displayed in Table 2. Also the correlation between predicted and observed $\mathrm{IC}_{50}$ are presented in Figure 2. This exposed the efficacy of the modeled equation as shown in equation 3 by predicting the $\mathrm{IC}_{50}$.

$\mathrm{pIC}_{50}=-15997.4-137.209(\mathrm{HOMO})+144.997(\mathrm{LUMO})-76.1468(\mathrm{BG})-0.672815(\mathrm{DM})-447.602(\mathrm{SE})-$ $12.1672(\mathrm{GN})+3.06587(\mathrm{HET})-0.340542(\mathrm{MW})-1.28901(\mathrm{Log} \mathrm{P})+0.520499(\mathrm{AREA})-24.0735(\mathrm{VOL})$ $+294.518(\mathrm{POL})+498.469(\mathrm{NNBL})+3193.02(\mathrm{NHBL})+24.7665(\mathrm{~N}+\mathrm{N})$

Table 2. Regression result for anti-colon cancer activity

\begin{tabular}{|c|c|c|c|c|c|}
\hline & $\begin{array}{c}\text { Predicted } \\
\mathbf{I C}_{\mathbf{5 0}}\end{array}$ & $\begin{array}{c}\text { Observed } \\
\mathbf{I C}_{\mathbf{5 0}}\end{array}$ & $\begin{array}{c}\text { Predicted } \\
\mathbf{I C}_{\mathbf{5 0}}\end{array}$ & $\begin{array}{c}\text { Observed } \\
\mathbf{I C}_{\mathbf{5 0}}\end{array}$ \\
\hline $\mathbf{A}_{\mathbf{a}}$ & 1.43 & 1.45 & $\mathbf{F}_{\mathbf{d}}$ & 3.84 & 3.86 \\
\hline $\mathbf{A}_{\mathbf{b}}$ & 0.81 & 0.78 & $\mathbf{G}$ & 1.52 & 1.1 \\
\hline $\mathbf{B}$ & 2.42 & 2.54 & $\mathbf{H}$ & 1.54 & 1.77 \\
\hline $\mathbf{C}$ & 3.51 & 3.75 & $\mathbf{I}$ & 0.92 & 0.62 \\
\hline $\mathbf{D}_{\mathbf{a}}$ & -0.27 & 0.1 & $\mathbf{J}$ & 0.21 & 0.13 \\
\hline $\mathbf{D}_{\mathbf{b}}$ & -0.09 & 0.09 & $\mathbf{K}$ & 3.76 & 4.01 \\
\hline $\mathbf{E}$ & 1.05 & 1.62 & $\mathbf{L}$ & 1.33 & 0.84 \\
\hline $\mathbf{F}_{\mathbf{a}}$ & 5.61 & 5.52 & $\mathbf{M}$ & 4.32 & 4.35 \\
\hline $\mathbf{F}_{\mathbf{b}}$ & 2.00 & 2.01 & $\mathbf{N}_{\mathbf{a}}$ & 0.96 & 0.22 \\
\hline $\mathbf{F}_{\mathbf{c}}$ & 3.11 & 3.24 & $\mathbf{N}_{\mathbf{b}}$ & 0.22 & 0.65 \\
\hline
\end{tabular}

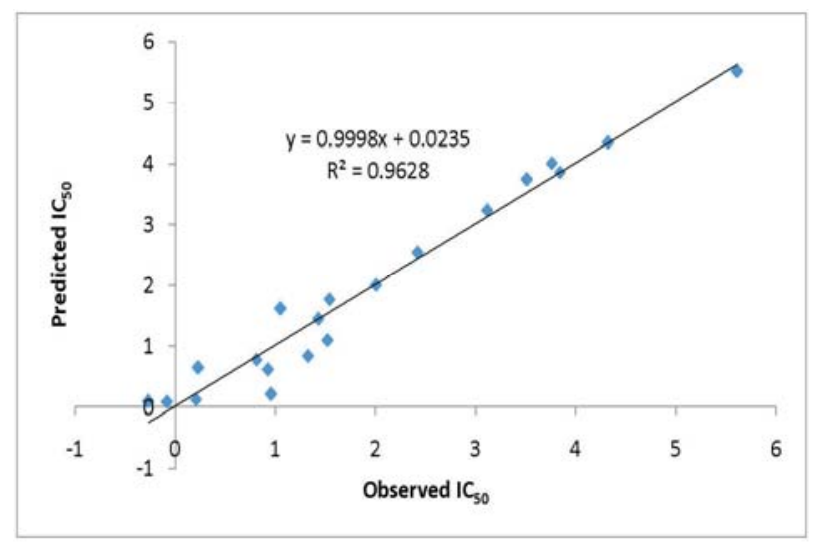

Fig. 2. The calculated predicted $\mathrm{IC}_{50}$ against the observed $\mathrm{IC}_{50}$

\section{QSAR model validation}

The major expediency of QSAR models is not only their capacity to replicate observed $\mathrm{IC}_{50}$, and confirm them using their fitting power $\left(\mathrm{R}^{2}\right)$; however, it is primarily their potential for predictive use. Therefore, the modeled QSAR validation was observed by considering $\mathrm{R}^{2}$, CV. $\mathrm{R}^{2}$ and adjusted $R^{2}$. The calculated $R^{2}$ is 0.962 ; which reveal an equitable fitness as well as the efficacy of the model as shown in equation 3. Also, the calculated CV.R ${ }^{2}$ was $0.999\{(>0.5)$ (standard)\} (Ponce et al 2004) and this showed the reliability and acceptability of the model as well as the adjusted $\mathrm{R}^{2}$ with 0.823 which is greater than 0.6 (standard). Thus, the QSAR model would be predictive. Furthermore, the plot of residual for the predicted $\mathrm{IC}_{50}$ against the observed $\mathrm{IC}_{50}$ is displayed in Figure 3 and it was observed that the plot did not show any reasonable inaccuracy. This is because the residuals propagation at the two sides of zero is indiscriminate.

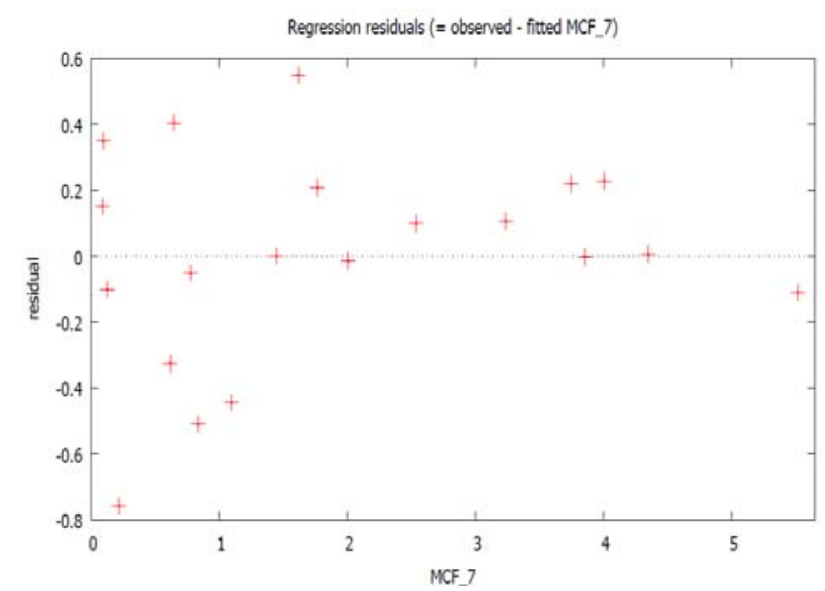

Fig. 3. The residuals versus observed $\mathrm{IC}_{50}$

\section{Molecular docking studies}

Docking studies were carried out using Discovery Studio (Discovery Studio version 2.5, 2009), autodock tool, autodockvina and pymol. The protein used was MCF-7 with PDB ID: $1 \mathrm{HI} 7$ (Williams et al 2001). The ligands were simulated and resulted to different conformations for individual molecular compound. The calculated binding affinity are $-4.7 \mathrm{Kcal} / \mathrm{mol},-4.1 \mathrm{Kcal} / \mathrm{mol},-4.2 \mathrm{Kcal} / \mathrm{mol}$, $-4.7 \mathrm{Kcal} / \mathrm{mol},-5.0 \mathrm{Kcal} / \mathrm{mol},-5.1 \mathrm{Kcal} / \mathrm{mol},-5.9$ $\mathrm{Kcal} / \mathrm{mol},-4.8 \mathrm{Kcal} / \mathrm{mol}, 29.7 \mathrm{Kcal} / \mathrm{mol}, 33.7$ $\mathrm{Kcal} / \mathrm{mol}, 32.3 \mathrm{Kcal} / \mathrm{mol},-5.8 \mathrm{Kcal} / \mathrm{mol},-4.0$ 
$\mathrm{Kcal} / \mathrm{mol}, \quad-4.6 \mathrm{Kcal} / \mathrm{mol}, \quad-4.9 \mathrm{Kcal} / \mathrm{mol}$, $-4.4 \mathrm{Kcal} / \mathrm{mol}, \quad-4.8 \mathrm{Kcal} / \mathrm{mol}, \quad-4.7 \mathrm{Kcal} / \mathrm{mol}$, $-4.2 \mathrm{Kcal} / \mathrm{mol},-1.9 \mathrm{Kcal} / \mathrm{mol}$ for $\mathbf{A}_{\mathbf{a}}-\mathbf{N}_{\mathbf{b}}$. As shown in Table 3, some of the compounds $\left(\mathbf{D}_{\mathbf{a}}, \mathbf{D}_{\mathbf{b}}, \mathbf{E}\right.$, and $\mathbf{G}$ ) acted very well as an anti-cancer agent. Moreover, highest binding energy conformation (i.e. conformation with more negative value) is presumed to be the best (i.e. Conformation with more negative value will require only small amount of energy to bind with the active site of the receptor). Therefore, as per the result, compound G $(-5.8)$ was found to be the best inhibitor among other pyrazole derivatives studied in this research work (Table 3) because it shows maximum docked energy (in term of negativity). The interaction between the ligand and the receptor of the few compounds with higher docking result is displayed in Figure 4.

Table 3. Binding affinity of Autodockvina of 1HI7 enzymes

\begin{tabular}{|c|c|c|c|}
\hline Mol & $\begin{array}{c}\text { Affinity } \\
\text { (Kcal/mol) }\end{array}$ & H-Bond between amino acid and drug & Distance \\
\hline $\mathbf{A}_{\mathbf{a}}$ & -4.7 & $\begin{array}{l}\text { (i) PHE-34, LIG: H (ii) PHE-34, LIG:0 } \\
\text { (iii) PHE-34, LIG:0 }\end{array}$ & $2.1,3.2,2.2$ \\
\hline$A_{b}$ & -4.1 & $\begin{array}{l}\text { (i) ASP-35, LIG: O(ii) PHE-34, LIG:N } \\
\text { (iii) PHE-34, LIG:N }\end{array}$ & $3.0,3.2,2.7$ \\
\hline B & -4.2 & PHE-34, LIG: $\mathrm{H}$ & 24 \\
\hline $\mathbf{C}$ & -4.7 & CYS-32, LIG: 0 & 3.3 \\
\hline $\mathbf{D}_{\mathbf{a}}$ & -5.0 & PHE-34, LIG: N (ii) PHE-34, LIG: H & $2.1,2.2$ \\
\hline $\mathbf{D}_{\mathrm{b}}$ & -5.1 & PHE-34, LIG:N & 2.1 \\
\hline $\mathbf{E}$ & -5.9 & $\begin{array}{l}\text { THR-49, LIG: H(ii) THR-49, LIG:N } \\
\text { (iii) THR-49, LIG: N }\end{array}$ & $2.7,2.0,2.3$ \\
\hline $\mathbf{F}_{\mathbf{a}}$ & -4.8 & PHE-34, LIG: $\mathrm{N}$ & 3.4 \\
\hline $\mathbf{F}_{\mathbf{b}}$ & 29.7 & PHE-34, LIG:N (ii) PHE-34, LIG:N & $2.5,2.0$ \\
\hline $\mathbf{F}_{\mathbf{c}}$ & 33.7 & $\begin{array}{l}\text { ASP-35, LIG: N (ii) VAL-9, LIG: } 0 \\
\text { (iii) VAL-9, LIG: N }\end{array}$ & $3.4,2.8,2.6$ \\
\hline $\mathbf{F}_{\mathbf{d}}$ & 32.3 & $\begin{array}{c}\text { VAL-9, LIG: N (ii) VAL-9, LIG: O } \\
\text { (iii) ASP-35, LIG: N }\end{array}$ & $2.5,2.5,3.2$ \\
\hline G & -5.8 & $\begin{array}{c}\text { PRO-47, LIG: N (ii) THR-49, LIG: N (iii) THR-49, LIG:N } \\
\text { (iv) THR-49, LIG: H }\end{array}$ & $3.2,2.2,2.0,2.7$ \\
\hline $\mathbf{H}$ & -4.0 & (i)ASP-35, LIG: $\mathrm{N}$ (ii) ASP-35, LIG: $\mathrm{H}$ & $3.3,2.2$ \\
\hline I & -4.6 & PHE-34, LIG: N (ii) PHE-34, LIG: H & $3.2,2.0$ \\
\hline $\mathbf{J}$ & -4.9 & GLU-13, LIG: N (ii) GLN-15, LIG: H (iii) GLN -15, LIG: N & $3.4,3.2,2.7$ \\
\hline $\mathbf{K}$ & -4.4 & $\begin{array}{l}\text { Cys-32, LIG:O (ii) PHE-34, LIG:O (iii) PHE-34, LIG: O } \\
\text { (iv) PHE-34, LIG: H(v) PHE-34, LIG: N }\end{array}$ & $3.2,2.1,3.6,2.4,3.2$ \\
\hline $\mathbf{L}$ & -4.8 & ARG-14, LIG: $\mathrm{O}$ (ii) THR-8, LIG: H & $2.6,2.5$ \\
\hline $\mathbf{M}$ & -4.7 & THR-49, LIG: H (ii) GLU-5, LIG: H & $2.3,2.1$ \\
\hline $\mathbf{N}_{\mathbf{a}}$ & -4.2 & $\begin{array}{l}\text { PHE-34, LIGO (ii) PHE-34, LIG:O } \\
\text { (iii) PHE-34, LIG:H (iv) ASP-35, LIG :N }\end{array}$ & $2.1,3.2,2.4,3.5$ \\
\hline $\mathbf{N}_{\mathrm{b}}$ & -1.9 & - & - \\
\hline
\end{tabular}

\section{CONCLUSION}

In present work, the result obtained via quantum chemical method (DFT) and QSAR (MLR) showed how effective the methods employed are and also revealed the potential of pyrazole derivatives as anti-cancer agent.

The model obtained from QSAR reproduced the observed $\mathrm{IC}_{50}$ using multiple linear regression via Gretl software. Also, in drug designing, the role played by the interaction between the ligand and the receptor are very crucial, therefore, the ligands simulated in this research work predicted stable conformations of the drug-like molecules (Pyrazole deriatives) in the active site of the enzyme.

Thus, the binding affinity of the interaction was acquired and compound $\mathbf{G}$ exhibited a better binding affinity. 

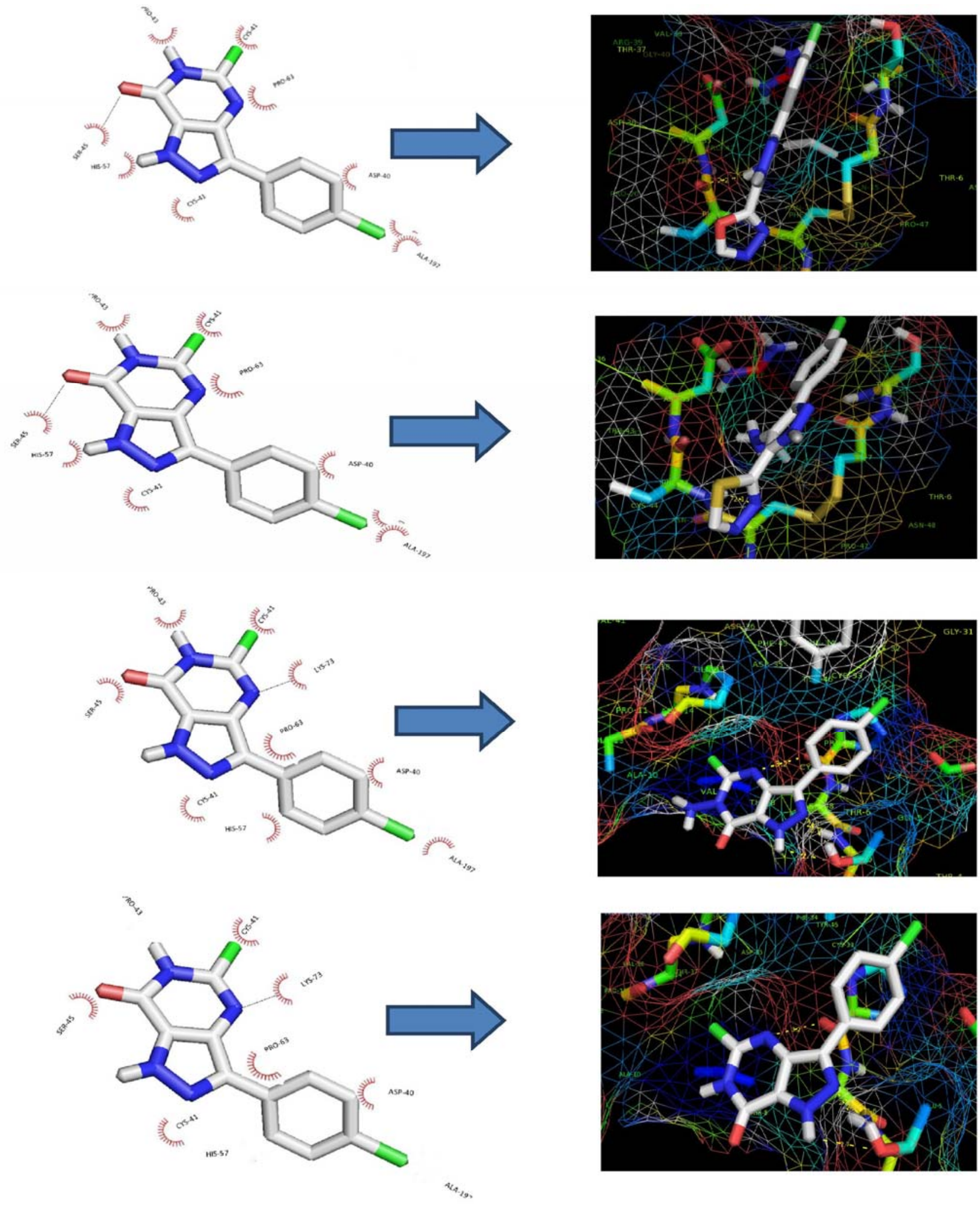

Fig. 4. Binding interactions for: (a) $\mathbf{D}_{\mathbf{a}}$ (b) $\mathbf{D}_{\mathbf{b}}$ (c) $\mathbf{E}$ and (d) $\mathbf{G}$ with $1 \mathrm{HI}$.

\section{REFERENCES}

Abass K, Reponen P, Mattila S, Pelkonen O. Metabolism of $\alpha$-thujone in human hepatic preparations in vitro. Xenobiotica 2011;41(2):101-11. [DOI: 10.3109/0049825 4.2010.528066]

Agarwal S, Mishra VK, Kumar V, Mishra M, Kashaw V, Kashaw SK. Exploring 2D and 3D QSAR studies of indole/benzoximidazole-5-carboximidine derivatives as anticancer agents for the development of predictive model. Bull. Pharm. Res. 2015a;5(3):84-95.

Agarwal S, Mishra VK, Mishra M, Singh S, Kumar V, Kashaw V, Kashaw SK. QSAR studies involving 2D, 3D QSAR and pharmacophore mapping studies on arylsulfonyl imidazolidinone derivatives as anticancer agents. Bull. Pharm. Res. 2015b;5(2):70-80. 
Aghaee F, Pirayesh Islamian J, Baradaran B. Enhanced radiosensitivity and chemosensitivity of breast cancer cells by 2-deoxy-d-glucose in combination therapy. J. Breast Cancer 2012;15(2):141-7. [DOI: 10.4048/jbc.2012. 15.2.141]

American Cancer Society. Breast Cancer Facts \& Figures 2017-2018. Atlanta: American Cancer Society, Inc. 2017.

Balasubramanian R, Vijaya Gopal R. Design and in silico analysis of ring-A monosubstituted chalcones as potential anti-inflammatory agents. Bull. Pharm. Res. 2012;2(2): 70-7.

Bansal H, Sharma A, Sharma V, Kumar V. Pharmacophore modeling studies on xanthones as monoamine oxidase-A inhibitors. Bull. Pharm. Res. 2011;1(1):15-21.

Balbi A, Anzaldi M, Macciò C, Aiello C, Mazzei M, Gangemi R, Castagnola P, Miele M, Rosano C, Viale M. Synthesis and biological evaluation of novel pyrazole derivatives with anticancer activity. Eur. J. Med. Chem. 2011;46(11):5293309. [DOI: 10.1016/j.ejmech.2011.08.014]

Bayani J, Yao CQ, Quintayo MA, Yan F, Haider S, D'Costa A, Brookes CL, van de Velde CJH, Hasenburg A, Kieback DG, Markopoulos C, Dirix L, Seynaeve C, Rea D, Boutros PC, Bartlett JMS. Molecular stratification of early breast cancer identifies drug targets to drive stratified medicine. npj Breast Cancer 2017;3:3. [DOI: 10.1038/s41523-016-0 003-5]

Becke AD. Density functional thermochemistry. III. The role of exact exchange. J. Chem. Phys. 1993;98(7):5648-52.

Bouachrine M, Hamidi M, Bouzzine SM, and Taoufik H. Theoretical study on the structure and electronic properties of new materials based on thiophene and oxadiazole. J. Appl. Chem. Res. 2009;10:29-37.

Dahiya R, Kumar A. Synthesis, spectral and anthelmintic studies on some novel imidazole derivatives. E-J. Chem. 2008;5(S2):1133-43. [DOI: 10.1155/2008/161783]

Dahiya R, Kumar A, Yadav R. Synthesis and biological activity of peptide derivatives of iodoquinazolinones/ nitroimidazoles. Molecules 2008;13(4):958-76.

Dahiya R, Mourya R. Synthetic studies on novel nitroquinazolinone analogs with antimicrobial potential. Bull. Pharm. Res. 2013;3(2):51-7.

Dahiya R, Mourya R, Agrawal SC. Synthesis and antimicrobial screening of peptidyl derivatives of bromocoumarins/methylimidazoles. Afr. J. Pharm. Pharmacol. 2010;4(5):214-25.

Dahiya R, Pathak D. Synthetic Studies on novel benzimidazolopeptides with antimicrobial, cytotoxic and anthelmintic potential. Eur. J. Med. Chem. 2007;42(6):77298. [DOI: 10.1016/j.ejmech.2006.11.015]

Discovery studio version 2.5, 2009. Accelrys, San Diego, California, USA.

Genin MJ, Biles C, Keiser BJ, Poppe SM, Swaney SM, Tarpley WG, Yagi Y, Romero DL. Novel 1,5-diphenylpyrazole nonnucleoside HIV-1 reverse transcriptase inhibitors with enhanced activity versus the delavirdine-resistant P236L mutant: Lead identification and SAR of 3- and 4substituted derivatives. J. Med. Chem. 2000;43(5):103440. [DOI: 10.1021/jm990383f]

Gottesman MM. Mechanisms of cancer drug resistance. Annu. Rev. Med. 2002;53:615-27. [DOI: 10.1146/annurev. med.53.082901.103929]

Hafez HN, El-Gazzar AR, Al-Hussain SA. Novel pyrazole derivatives with oxa/thiadiazolyl, pyrazolyl moieties and pyrazolo[4,3-d]-pyrimidine derivatives as potential antimicrobial and anticancer agents. Bioorg. Med. Chem. Lett. 2016;26(10):2428-33. [DOI: 10.1016/j.bmcl.2016.0 3.117]
Hansch C. Quantitative approach to biochemical structure-activity relationships. Acc. Chem. Res. 1969;2(8):232-9. [DOI: 10.1021/ar50020a002]

Harris RE, Alshafie GA, Abou-Issa H, Seibert K. Chemoprevention of breast cancer in rats by celecoxib, a cyclooxygenase 2 inhibitor. Cancer Res. 2000;60(8):21013.

Harrison WA. Pseudo-potentials in the theory of metals (Frontiers in physics), 1st edition, W. A. Benjamin, Inc., New York: 1966.

Jacquemin D, Perpete EA, Ciofini I, Adamo C. Accurate simulation of optical properties in dyes. Acc. Chem. Res. 2009;42(2):326-34. [DOI: 10.1021/ar800163d]

Jain J, Bansal SK, Chowdhury P, Sinha R, Tripathi U, Malhotra M. In silico pharmacophore validation of anticonvulsant activity of (E) ( \pm )-3-menthone derivatives. Bull. Pharm. Res. 2013;3(3):146-56.

Jemal A, Bray F, Center MM, Ferlay J, Ward E, Forman D. CA Cancer J. Clin. 2011;61(2):69-90. [DOI: 10.3322/caac.201 07]

Lee C, Yang W, Parr RG. Development of the Colle-Salvetti correlation-energy formula into a functional of the electron density. Phys. Rev. B 1988;37(2):785-9. [DOI: 10.1103/PhysRevB.37.785]

Lewis DF, Broughton HB. Molecular binding interactions: their estimation and rationalization in QSARs in terms of theoretically derived parameters. Sci. World J. 2002;2: 1776-802. [DOI: 10.1100/tsw.2002.343]

McMurry J, Fay RC. Chemistry, fourth edition, Prentice Hall, Inc., New Jersey: 2004.

Meanwell NA. Synopsis of some recent tactical application of bioisosteres in drug design. J. Med. Chem. 2011;54(8): 2529-91. [DOI: 10.1021/jm1013693]

Oyebamiji KA, Semire B. Studies of 1, 4-dihydropyridine derivatives for anti-breast cancer (MCF-7) activities: Combinations of DFT-QSAR and docking methods. New York Sci. J. 2016a;9(6):58-66. [DOI: 10.7537/marsnys 090 61610]

Oyebamiji AK, Semire B. DFT-QSAR model and docking studies of antiliver cancer (HEPG-2) activities of 1, 4diydropyridine based derivatives. Cancer Bio. 2016b; 6(2):69-78. [DOI: 10.7537/marscbj06021610]

Oyebamiji AK and Semire B. Studies of anti-hypertensive activity of 1, 4-dihydropyridine derivatives: combinations of DFT-QSAR and docking approaches. Bull. Pharm. Res. 2016c;6(3):105-13. [DOI: 10.21276/bpr.2016.6.3.4]

Pereira NP, Monteiro TM, Freitas AC, Barreiro EJ, Miranda AL. Synthesis and analgesic properties of new 5-thioaryl pyrazole derivatives. Boll. Chim. Farm. 1998;137(3):82-6.

Ponce YM, Garit JAC, Torrens F, Zaldivar VR, Castro EA. Atom, atom-type, and total linear indices of the "molecular pseudograph's atom adjacency matrix": application to QSPR/QSAR studies of organic compounds. Molecules 2004;9(12):1100-23.

Pourbasheer E, Riahi S, Ganjali MR, Norouzi P. Application of genetic algorithm-support vector machine (GA-SVM) for prediction of BK-channels activity. Eur. J. Med. Chem. 2009;44(12):5023-8. [DOI: 10.1016/j.ejmech.2009.09.00 6]

Prakash 0, Kumar R, Parkash V. Synthesis and antifungal activity of some new 3-hydroxy-2-(1-phenyl-3-aryl-4pyrazolyl) chromones. Eur. J. Med. Chem. 2008;43(2):43540. [DOI: 10.1016/j.ejmech.2007.04.004]

Rani S, Ajeet, Kumar A. Designing of sulfanilamide/ sulfacetamide derivatives as human topoisomerase II Inhibitor: A docking approach. Am. J. Pharmacol. Sci. 2014; 2(2):42-6. [DOI: 10.12691/ajps-2-2-3] 
Ruiu S, PinnaGA, Marchese G, Mussinu JM, Saba P, Tambaro S, Casti P, Vargiu R, Pani L. Synthesis and characterization of NESS 0327: A novel putative antagonist of the CB1 cannabinoid receptor. J. Pharmacol. Exp. Ther. 2003; 306(1):363-70. [DOI: 10.1124/jpet.103.049924]

Sharma V, Kumar V. Efficient way of drug designing: A comprehensive review on computational techniques. Bull. Pharm. Res. 2014;4(3):118-23.

Sharma V, Sharma PC, Kumar V. Indolizine derivatives as phosphodiesterase IV inhibitors: development and validation of pharmacophore models. Bull. Pharm. Res. 2016;6(2):68-73. [DOI: 10.21276/bpr.2016.6.2.5]

Sharma V, Wakode SR, Lather V, Mathur R, Fernandes MX. Structure based rational drug design of selective phosphodiesterase-4 ligands as anti-inflammatory molecules. Bull. Pharm. Res. 2011;1(2):33-40.

Spartan 14 wave function Inc. Irvine, CA 92612, USA.
Storer R, Ashton CJ, Baxter AD, Hann MM, Marr CLP, Mason AM, Mo C-L, Myers PL, Noble SA, Penn CR, Weir NG, Woods JM, Coe PL. The synthesis and antiviral activity of 4-fluoro-1- $\beta$-D-ribofuranosyl-1H-pyrazole-3-carboxamide. Nucleosides Nucleotides Nucleic Acids 1999;18(2): 203-16. [DOI: 10.1080/1525777990804306 8]

Taylor RD, Jewsbury PJ, Essex, JW. A review of proteinsmall molecule docking methods. J. Comput. Aided Mol. Des. 2002;16(3):151-66.

Williams MA, Westley BR, May FEB, Feeney J. The solution structure of the disulphide-linked homodimer of the human trefoil protein TFF1. FEBS Lett. 2001;493(2-3): 70-4. [DOI: 10.1016/S0014-5793(01)02276-1]

Yang L, Feng J-K, Ren A-M. Theoretical studies on the electronic and optical properties of two thiophenefluorene based $\pi$-conjugated copolymers. Polymer 2005; 46(24):10970-82. [DOI: 10.1016/j.polymer.2005.0 9.050] 